\title{
Effects of induced weight shift in the hind limbs on claw loads in dairy cows
}

\author{
K. Nuss, ${ }^{1 *}$ J. Müller, ${ }^{1}$ and T. Wiestner ${ }^{2}$ \\ ${ }^{1}$ Farm Animal Surgery Division, Farm Animal Department, Vetsuisse Faculty \\ ${ }^{2}$ Equine Sports Medicine Unit, Equine Department, Vetsuisse Faculty, University of Zurich, Winterthurerstrasse 260, CH-8057 Zurich, Switzerland
}

\section{ABSTRACT}

The modern dairy industry is plagued by a high prevalence of claw horn lesions in cows, which cause lameness, affect well-being, limit milk production, and are responsible for premature removal of cows from the herd. The lateral hind claws are primarily affected, and this has been linked to a relatively higher load being exerted on the lateral claws when cows shift weight from one hind limb to the other. The vertical ground reaction forces and mean and maximum pressures under the claws were measured in 40 nonlame dairy cows before and during a shift in weight from one hind limb to the other, which was accomplished by applying pressure manually to one side of the pelvis. During square standing on firm ground, about two-thirds of the entire hind limb load was exerted on the 2 lateral claws, and the remaining one-third was exerted on the medial claws combined. At the moment of maximum weight shift, the lateral claw of the loaded limb bore almost two-thirds of the entire load of both hind limbs, with the heel zone bearing almost half of the load of both hind limbs. Subsequently, the load of the lateral claw of the contralateral hind limb decreased, as did the load of both medial claws. Thus, the weight redistribution had occurred predominantly between the lateral hind claws. The high load exerted on a lateral hind claw during weight shift and at maximum weight shift is assumed to play a role in the pathogenesis of claw horn lesions, particularly when accentuated by a softened claw horn and hard flooring.

Key words: dairy cow, hind limb, weight distribution, lateral claw

\section{INTRODUCTION}

Industrialization of milk production, especially yearround housing of many cows on hard flooring, dur-

Received August 10, 2018.

Accepted March 21, 2019.

*Corresponding author: karl.nuss@uzh.ch ing the last few decades has been accompanied by a lameness prevalence in dairy cows that is considered unacceptably high in many parts of the world (Huxley and Green, 2010; Griffiths et al., 2018). Among the causes of lameness, claw horn lesions commonly affect the overall health and well-being of cows, cause painful lameness, and lead to decreased milk production and premature removal of cows from the herd because of deep sepsis (Cramer et al., 2009; Shearer and van Amstel, 2017). Furthermore, lame dairy cows negatively affect consumer perception of wholesome food from healthy animals (Cardoso et al., 2016).

Claw horn lesions, especially sole ulcer and whiteline disease, have been associated with many factors including calving-related hormonal changes, lack of cow comfort, poor claw conformation, ruminal acidosis and laminitis, and changes in the fat content and composition of the digital cushion (Räber et al., 2006; Bicalho et al., 2009; Shearer and van Amstel, 2017). Even though these factors usually affect all claws of a cow equally, sole ulcer and white-line disease occur almost exclusively in the lateral claws of the hind limbs. This predilection led to the hypothesis that anatomical or mechanical differences between the claws are involved in the pathogenesis of lesions in the lateral claws of the hind limbs (Andersson and Lundström, 1981; Ossent et al., 1987; Toussaint Raven, 1992; Nuss and Paulus, 2006).

Asymmetry in size and shape of the lateral and medial hind claws is commonly seen in dairy cows housed indoors. A higher proportion of load on the lateral hind claw was thought to be the cause of the asymmetry (Ossent et al., 1987; Toussaint Raven, 1992; van der Tol et al., 2003, 2004; Nuss and Paulus, 2006). The goal of Toussaint Raven (1992) and van der Tol et al. (2002) was to distribute the load evenly in all 4 hind claws of a healthy cow by proper foot trimming. Their studies (van der Tol et al., 2003, 2004) have shown that even in cows with healthy and well-trimmed feet, weight bearing is not symmetrical between paired hind claws and that the lateral claws bear more weight than the medial claws. Functional claw trimming resulted in balanced weight bearing between paired claws only when the 
sole of the lateral claws was thinned considerably and only for a short period of time, and a return to asymmetrical weight bearing occurred after a few months (Kehler and Gerwing, 2004; Nuss and Paulus, 2006). However, when weight shifts from square standing to mainly one hind limb, Toussaint Raven (1992) assumed that the lateral claw of the loaded foot would undergo a higher load than that of the contralateral foot. To the authors' knowledge, the load stresses on the claws resulting from shifting of weight (Chapinal et al., 2011) have not been quantified. The goal of our study was to measure the vertical ground reaction force and pressure distribution on the trimmed hind limb claws of dairy cows during square standing (SQS) and at the moment of maximum weight shift (MWS), when the cows were manipulated to distribute their weight from square standing to mainly one hind limb.

\section{MATERIALS AND METHODS}

\section{Animals}

We examined 40 nonlame dairy cows (15 Brown Swiss, 20 Holstein-Friesian, and 5 Red-Holstein) with a mean age of 50 mo (range: 25-86 mo) and a mean BW of 638 $\mathrm{kg}$ (range: $470-920 \mathrm{~kg}$ ) and in their first to fifth lactation. Owner consent was obtained before the trials, and the study was approved by the veterinary authorities of the Canton of Zurich, Switzerland (permission no. ZH 144/15). Twenty-three cows were from freestall herds, and 17 were from tiestall herds. The time of the last foot trimming varied, but none of the cows had severely overgrown or deformed claws. Before the measurements were made, the cows were scored for signs of lameness and placed in a hoof trimming chute, and the hind feet were examined for lesions. Then, the claws were trimmed by the authors according to the principles of Toussaint Raven (1992). The foreclaws were trimmed at the same time if required. Mild heel horn erosion or stage M1 and M3 digital dermatitis were treated with tetracycline spray and were tolerated for this study as long as they did not cause any lameness before and after trimming. During the measurement period, which lasted $3 \mathrm{~d}$, the cows were stabled in tiestalls with a soft, 2.5-cm-thick rubber mat and bedded with 10 to $15 \mathrm{~cm}$ of straw. The cows were fed hay, grass silage, corn silage, and minerals and had access to water ad libitum. All cows remained healthy during the study and returned safely to the herds of origin.

\section{Experimental Setup}

The measuring system consisted of a force plate with a pressure plate placed on top of it, which was inte- grated into a large, custom-built examination platform (construction: Vetsuisse Faculty, University of Zurich, Switzerland; Figure 1). This platform (width: $1.08 \mathrm{~m}$; length: $2.40 \mathrm{~m}$ ) was mobile and had 4 supports, which could be adjusted in height to level out the platform surface. The standing area of the platform for the cows was made up of 5 bench-like aluminum modules that had the same dimensions as the measuring plates. For the present study, the force plate was firmly mounted between the first and the third of these modules, with its long side orientated transversally to the platform. The surface of the platform modules was covered with a solid, nonslip rubber mat $(3 \mathrm{~cm}$ thick $)$, which made the platform modules surface level with the pressure plate surface on top of the force plate (Figure 1). A soft rubber mat (5 mm thick) was used to cover the entire platform, including the sensing area, to protect the latter from possible mechanical damage from the sharp edges of the claw sole. Adjustable aluminum rods were mounted on the edges of the platform to restrict the cows' movements during the measurements (Figure 1). Movable ramps (1 ramp placed at each end) placed at both ends made it easy for the cows to step on and off the platform.

\section{Instrumentation}

The force plate (type FP-9907-03-0007, AMTI, Watertown, MA) was $108 \mathrm{~cm} \times 42 \mathrm{~cm} \times 18 \mathrm{~cm}$ in size and was able to determine 3 -dimensional (xyz) ground reaction force based on strain gauge sensors. In the present study, 2 hind limbs were always situated on the sensing area, and only the combined total vertical ground reaction force (vGRF) was determined within a load range of $10 \mathrm{kN}$ (which corresponds to $\sim 980 \mathrm{~kg}$ mass).

The pressure plate (footscan, RSscan International, Olen, Belgium) had the same horizontal size $(107 \mathrm{~cm}$ $\times 42 \mathrm{~cm}$ ) as the force plate on which it was placed and contained 8,192 pressure sensors as a $128 \times 64$ matrix in a sensing area of $97.5 \mathrm{~cm} \times 32.5 \mathrm{~cm}$. Each sensor had an active area of $0.762 \mathrm{~cm} \times 0.508 \mathrm{~cm}$, corresponding to a density of 2.6 sensors $/ \mathrm{cm}^{2}$ and a maximum pressure capacity of $2 \mathrm{MPa}\left(200 \mathrm{~N} / \mathrm{cm}^{2}\right)$.

A software program (Footscan 7.7 Second Generation, RSscan International) was used for synchronized acquisition of the total vGRF and the pressure distribution picture via an interface box (Figure 1). Each measurement was manually started and lasted $5 \mathrm{~s}$, during which 500 single data sets (each containing 1 vGRF and 8,192 pressure values) were sampled at a frequency of $100 \mathrm{~Hz}$. The software also controlled the calibration processes. Before the first measuring task of each cow and with an empty platform, the force plate and pressure plate were calibrated to a zero-load status. 


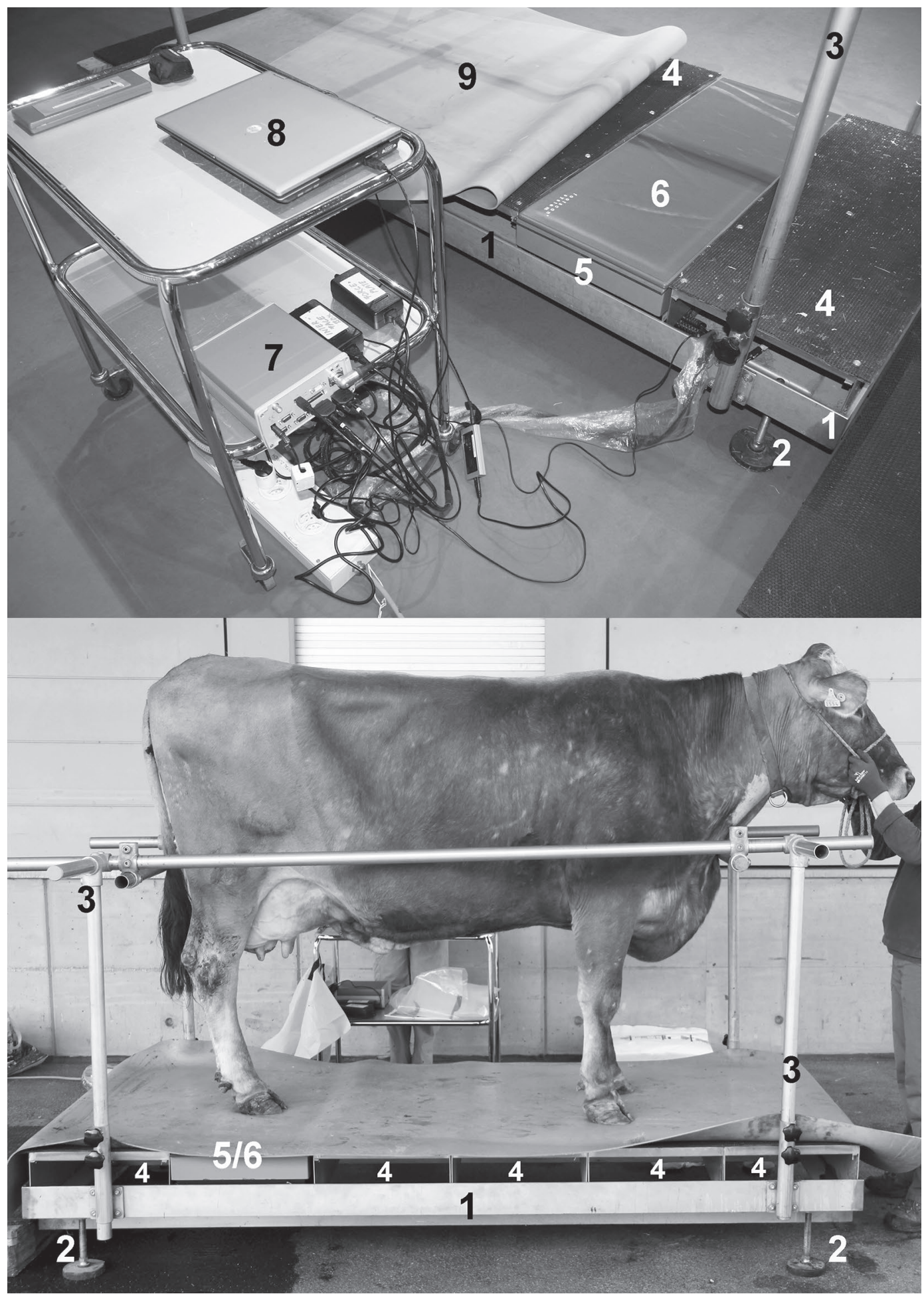

Figure 1. Measurement setup with platform, consisting of an aluminum frame (1) and adjustable supports for horizontal alignment (2), aluminum rods for restriction of the cow's movements (3), and standing space comprising several bench-like aluminum modules (4). Force (5) and combined pressure plate (6) placed between the modules and level with the standing area (4). Interface box (7) for calibration of force and pressure plate and for data transfer to a personal computer (8). Protective soft rubber mat (9). 
During measurements, a real-time recalibration process was carried out by applying the following relationships: the stacked arrangement of the equipment necessitated that the total vGRF determined by the force plate was equal to the total force $\left(\mathrm{F}_{\text {tot }}\right)$ measured by the pressure plate as $\mathrm{F}_{\text {tot }}=\Sigma \mathrm{F}_{\mathrm{i}}$, with i denoting a single pressure sensor and $\Sigma$ denoting the sum over all sensors of the pressure plate. Furthermore, because each pressure sensor had the same sensing area $\left(A_{s}\right)$, the partial forces were calculated as $\mathrm{F}_{\mathrm{i}}(\mathrm{N})=\mathrm{A}_{\mathrm{s}}\left(\mathrm{m}^{2}\right) \times \mathrm{P}_{\mathrm{i}}(\mathrm{Pa})$, with $\mathrm{P}_{\mathrm{i}}$ denoting the pressure. As a consequence, the expression $\operatorname{vGRF}(\mathrm{t})=\mathrm{A}_{\mathrm{s}} \times \Sigma \mathrm{P}_{\mathrm{i}}(\mathrm{t}) \times \mathrm{C}_{\text {cal }}$, with $\mathrm{C}_{\text {cal }}$ being an adjustable calibration coefficient (default value: $\mathrm{C}_{\text {cal }}$ $=1$ ), could be used to recalibrate the pressure values for each repetitive sampling time point $(\mathrm{t})$. Additionally, this equation revealed that the force distribution among the sensor cells was directly proportional to the pressure distribution determined by the pressure plate. This made it possible to determine a partial vGRF by totaling the respective sensor forces within a discrete area (e.g., the lateral claw).

\section{Experimental Protocol}

The cows were guided onto the platform, with the hind feet standing on the pressure plate. For each measurement trial, the claw prints, the center of pressures for the hind feet, and the vGRF of each foot were directly displayed on the computer screen, which allowed an instant assessment of the position of the feet and the balance in weight bearing. In the starting position, the cow stood squarely with the hind feet placed symmetrically and both feet loaded evenly (SQS). Thereafter, the 5-s measurement was started. During this time, a shift in weight from the left hind limb to the right hind limb was induced by a horizontal force, which was manually applied at the location of the left hip joint. To standardize the weight shifting, it was necessary for both of the cow's hind feet to remain in contact with the ground during the height of the weight shift (MWS) and to return toward the SQS position after manual force at the hip joint was released. If the cow resisted the translational manipulation or did not shift back toward a balanced position at the end of the measurement, the data were not analyzed and the measurement was repeated.

\section{Data Processing and Statistics}

For each cow, the acquired 500 single data sets were stored in an Excel (Microsoft Corp., Redmond, WA) file. To assess the effects of the weight shift, only the data sets of the SQS and MWS positions were further evaluated. The very first of the 500 data sets (ds $=$
1/500) was analyzed for the SQS position, whereas for the MWS position the data set of the time point in which the right hind limb showed its maximum vGRF (ds = maximum vGRF/500, right hind limb) was analyzed. For these SQS and MWS data sets, digital templates were used to divide the claws into a sole zone and a heel zone. A custom-made Excel analysis worksheet was used to extract the partial vGRF $(\mathrm{N})$, the imprint of the claw soles on the ground $\left(\mathrm{cm}^{2}\right)$, the mean pressure $(\mathrm{kPa})$, and the maximum pressure $(\mathrm{kPa})$, respectively, for each foot, each claw, and both claw zones. All extracted variables were then exported into SPSS (IBM SPSS Statistics, version 23, IBM, Armonk, NY), which was used for statistical analysis. The Shapiro-Wilk test was used to test the data for normality. Normally distributed data were compared with a paired $t$-test, and non-normally distributed data were compared with the Wilcoxon signed-rank test. Differences were considered significant at $P<0.05$.

\section{RESULTS}

\section{Force Distribution Between Limbs, Claw, and Claw Zones}

The vGRF measured in the hind limbs were in agreement with the BW measured on the weighbridge. In the SQS position, $49 \%$ of the vGRF was exerted on the left hind limb and $51 \%$ was exerted on the right hind limb. At MWS, $23 \%$ of the vGRF was exerted on the less-loaded left hind limb compared with $77 \%$ on the loaded right hind limb.

At SQS, the percentages of the mean force distribution between the medial and lateral claws of the left hind limb were 17 and $32 \%$ of the vGRF of both hind limbs, and in the right hind limb they were 16 and $35 \%$. Thus, in the SQS position, about one-third of the entire hind limb force was exerted on the 2 medial claws combined, and the remaining two-thirds was exerted on each of the lateral claws (Table 1). At MWS, $14 \%$ of the overall hind limb vGRF was exerted on the medial claw, and $8.5 \%$ was exerted on the lateral claw in the left hind limb. In the loaded right hind limb, $13 \%$ of the overall vGRF was exerted on the medial claw, and $64.5 \%$ of the entire hind limb vGRF was exerted on the lateral claw (Figure 2). There was no significant difference in vGRF of the medial claws of the loaded and less-loaded limbs. Two-thirds of the entire vGRF of both hind limbs acted on the loaded lateral claw at MWS.

Regarding the claw zones at SQS, the vGRF acting on the lateral claw zones were significantly higher than those acting on the medial claw zones. The vGRF exerted on the heel zones were significantly greater than 
Table 1. Vertical ground reaction forces (in N) of the hind limbs of 40 dairy cows with trimmed claws during square standing (SQS) and at the maximum of induced weight shift (MWS) to the right hind limb ${ }^{1}$

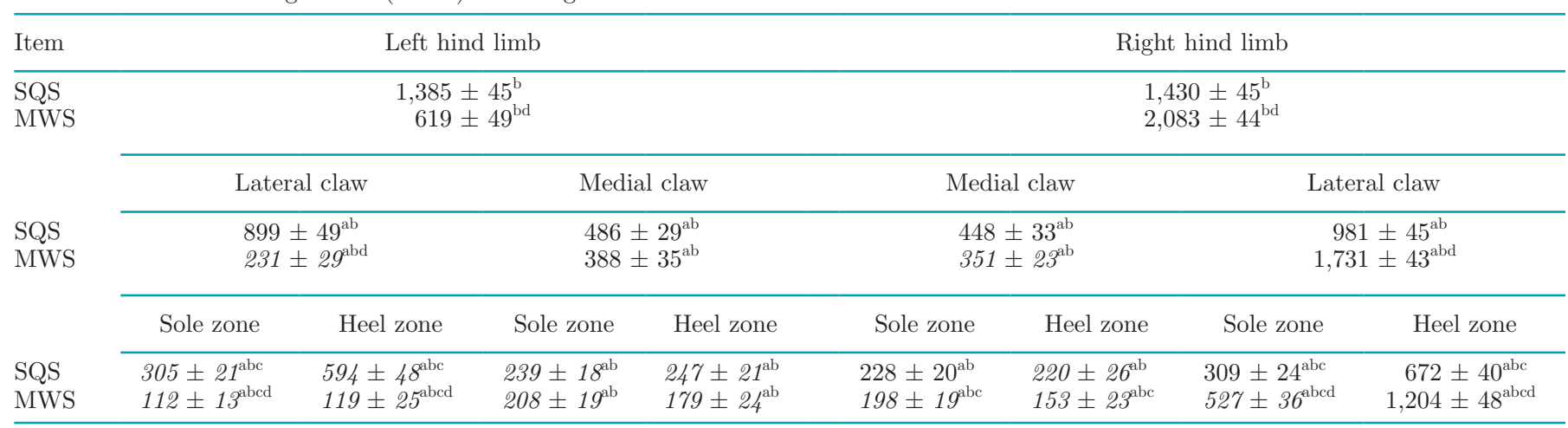

${ }^{\mathrm{a}-\mathrm{d}}$ Values with letters differ significantly $(P<0.05){ }^{\mathrm{a}}$ between lateral and medial claws of the same limb, ${ }^{\mathrm{b}}$ between SQS and MWS, ${ }^{\mathrm{b}}$ between sole and heel zones, and ${ }^{\mathrm{d}}$ between the respective zones of the left and right hind limbs.

${ }^{1}$ Mean \pm SEM. Regular font for normally distributed data; italic font for non-normally distributed data.

those exerted on the sole zones in the lateral claws but not in the medial claws (Table 1). At MWS, the vGRF of the medial claws and their sole and heel zones were significantly smaller compared with SQS. In addition, the vGRF exerted on the sole zones of the less-loaded left hind limb claws were greater than those exerted on the heel zones. This indicated a weight shift from the heel zones to the sole zones, resulting in a relief of force in the lateral claw heel zone of the left hind limb. In contrast, there was a marked increase in vGRF of the loaded lateral claw heel zone of the right hind limb. Almost $50 \%$ of the vGRF of the 2 hind limbs was acting on the heel zone of the loaded lateral claw at MWS (Table 1).

\section{Claw Imprints}

In the SQS position, the combined imprints of the paired claws (limb imprints), the imprints of the lateral claws, and the imprints of the medial claws did not differ between the 2 hind limbs. However, the lateral claws had significantly larger imprints than the medial claws and larger sole and heel zones than the medial claws. In all claws, the heel zone had a significantly larger imprint than the sole zone (Table 2). At MWS, the means of the imprints of the less loaded left hind limb decreased significantly; the imprint of the lateral claw was reduced to $50 \%$ and the imprint of the medial claw to $74 \%$ of the SQS values. The means of the total imprint of the loaded right hind limb remained unchanged, but the imprint of the lateral claw increased significantly from 46.5 to $50.8 \mathrm{~cm}^{2}$ (9\%; Table 2). The imprint of the medial claw decreased significantly. Regarding the claw zones, the imprint of the heel zone of the lateral claw became smaller than the imprint of the sole zone in the less-loaded left hind limb. The imprints of the medial claws and their zones did not differ significantly between the left and right hind limbs. The imprint of the heel zone of the loaded lateral claw increased significantly (Table 2; Figure 3).

\section{Pressure Distribution Between Limbs, Claws, and Claw Zones}

In the SQS position, the mean pressure ranged from $128 \mathrm{kPa}$ in the medial claws to $210 \mathrm{kPa}$ in the lateral claws (Table 3). The lateral claws underwent significantly higher mean pressures than the medial claws. The highest mean pressure was recorded at the heel zone of the lateral claws, and the lowest mean pressure was recorded at the heel zone of the medial claws. At MWS, the mean pressures under the lateral claw of the less-loaded left hind limb decreased significantly. The mean pressure under the medial claw of this limb remained unchanged (Table 3). The mean pressure under the claws of the loaded right hind limb increased significantly. The highest mean pressure of $408 \mathrm{kPa}$ was measured under the heel zone of the loaded lateral claw (Table 3). A significant decrease in mean pressure was recorded in the medial claw of the loaded right hind limb at MWS compared with SQS.

In the SQS position, the maximum pressures (Table 4) under the left and right hind limbs did not differ significantly. However, the lateral claws underwent significantly higher maximum pressures than the medial claws. Although the maximum pressures of the heel and sole zones did not differ in the medial claws, they differed significantly in the lateral claws. At MWS, the maximum pressures under the less-loaded left hind limb decreased significantly. The maximum pressures under both zones of the lateral claw of this limb decreased significantly, whereas those of the medial claw remained 
Table 2. Imprints (in $\mathrm{cm}^{2}$ ) of the hind limbs of 40 dairy cows with trimmed claws during square standing (SQS) and in the moment of maximum induced weight shift (MWS) to the right hind limb ${ }^{1}$

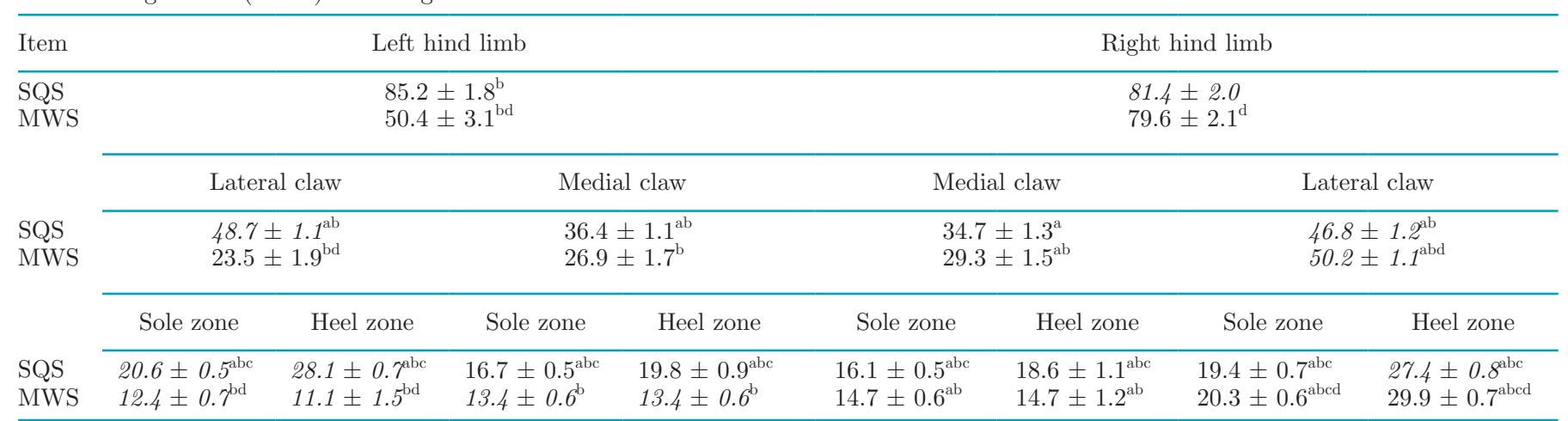

${ }^{\mathrm{a}-\mathrm{d}}$ Values with letters differ significantly $(P<0.05){ }^{\mathrm{a}}$ between lateral and medial claws of the same limb, ${ }^{\mathrm{b}}$ between SQS and MWS, ${ }^{\mathrm{c}}$ between sole and heel zones, and ${ }^{\mathrm{d}}$ between the respective zones of the left and right hind limbs.

${ }^{1}$ Mean \pm SEM. Regular font for normally distributed data; italic font for non-normally distributed data.

unchanged (Table 4). The maximum pressure under the loaded right hind limb increased significantly even though the maximum pressure under the medial claw decreased significantly, resulting in mean maximum pressures under the lateral claw that were 3 times those under the medial claws. The greatest maximum pressures were measured under the heel zone of the lateral claw of the loaded limb.

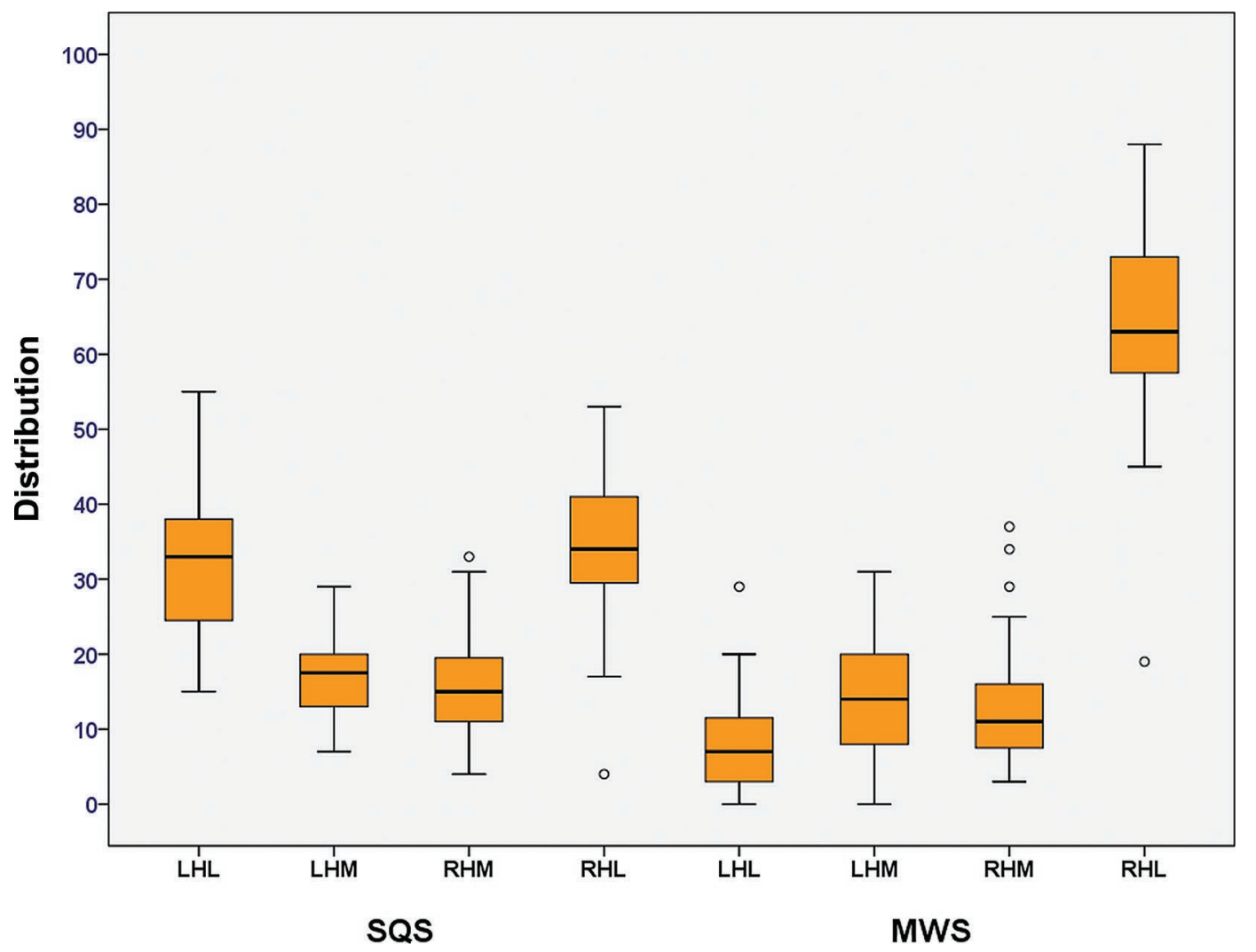

Figure 2. Distribution of the means of the percentages of vertical ground reaction force (vGRF) among the hind limb claws in 40 cows in the square standing (SQS) data set and maximum induced weight shift (MWS) data set. LHL = left hind lateral claw, LHM = left hind medial claw, RHM = right hind medial claw, RHL = right hind lateral claw. Left side: SQS with even weight bearing in hind limbs. Approximately one-third of the entire hind limb vGRF is exerted on each of the lateral claws and on the 2 medial claws combined. Right side: Distribution of vGRF at MWS. Approximately two-thirds of the entire hind limb force is exerted on the loaded lateral claw while the other claws are less loaded. Box contains $50 \%$ of the values and shows the median (band inside the box) and the lower and upper quartile. Whiskers represent interquartile range $\times 1.5$ or minimum/maximum values. Dots represent outliers. 


\section{DISCUSSION}

There was a disparity of load distribution in the trimmed claws of dairy cows, even in the SQS position. About one-third of the entire vGRF of both hind limbs was exerted on each of the lateral hind claws, and the remaining one-third was exerted on the medial claws combined. At MWS, this disparity had increased markedly further so that two-thirds of the entire vGRF of both hind limbs was now exerted solely on the loaded lateral claw. It is conceivable that such a load disparity at SQS and its exacerbation at MWS may be noteworthy factors in the development of claw horn lesions in the lateral claws of the hind limbs of dairy cows.

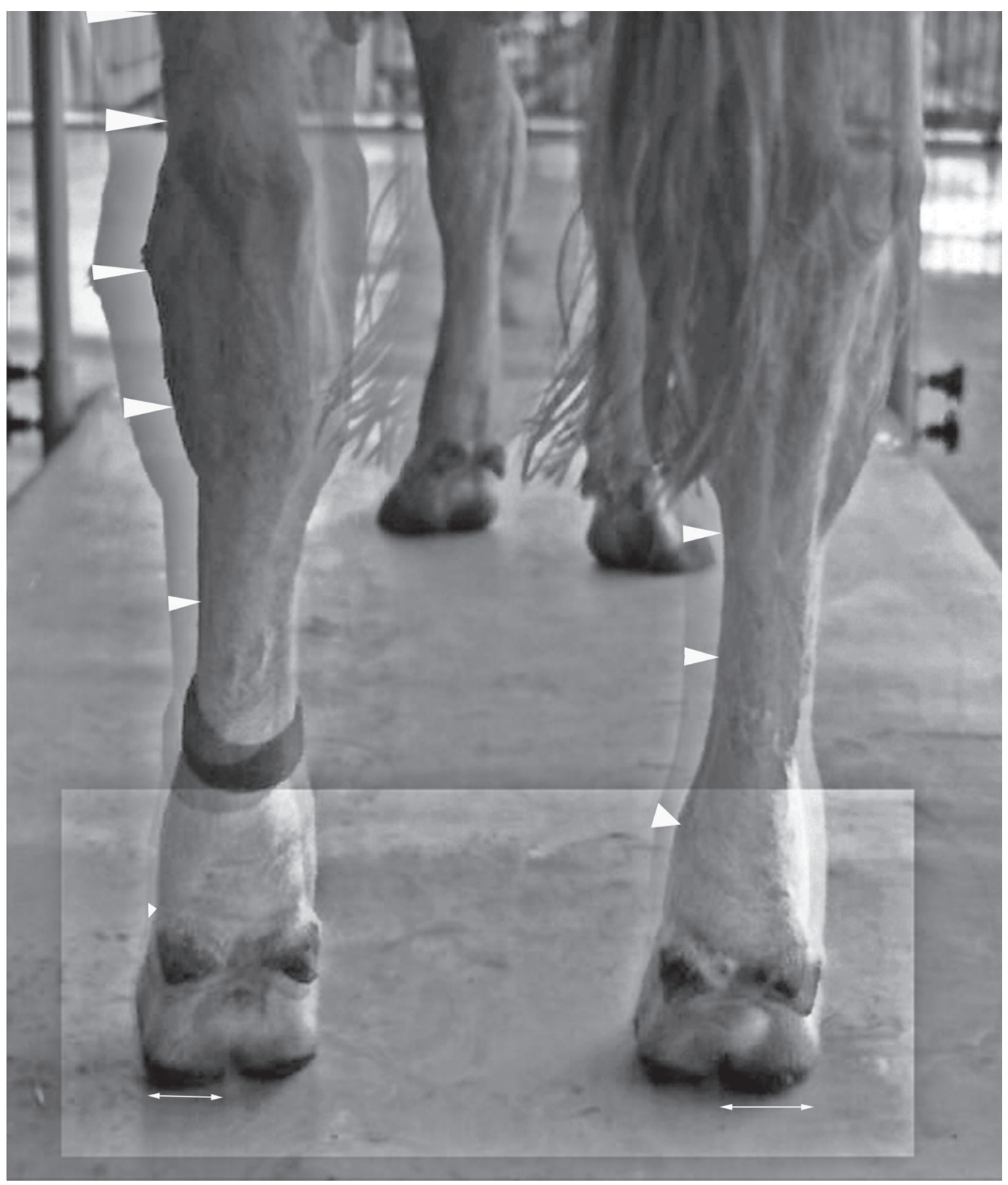

Figure 3. Two screenshots from the same high-speed cinematographic video of a cow's hind limbs square standing (SQS) and maximum induced weight shift (MWS). The images were assembled and made semitransparent with a software tool (Adobe Photoshop CS6 Version 13.0 $\times 64$, Adobe Systems Incorporated, San Jose, CA). The shadow to the left side of the limbs indicates the limbs in the SQS position, the arrowheads indicate the shift, and the solid limbs are at MWS. It is evident that only the upper limb regions shifted and that the claws remained in the same spot, with only minor x- and y-ground reaction forces. At MWS, the heel of the lateral claw of the right hind limb is wider than that of the left hind limb (small double arrows), likely due to extra compression. 
Table 3. Mean pressures (in $\mathrm{kPa}$ ) of the hind limbs of 40 dairy cows with trimmed claws during square standing (SQS) and in the moment of maximum induced weight shift (MWS) to the right hind limb ${ }^{1}$

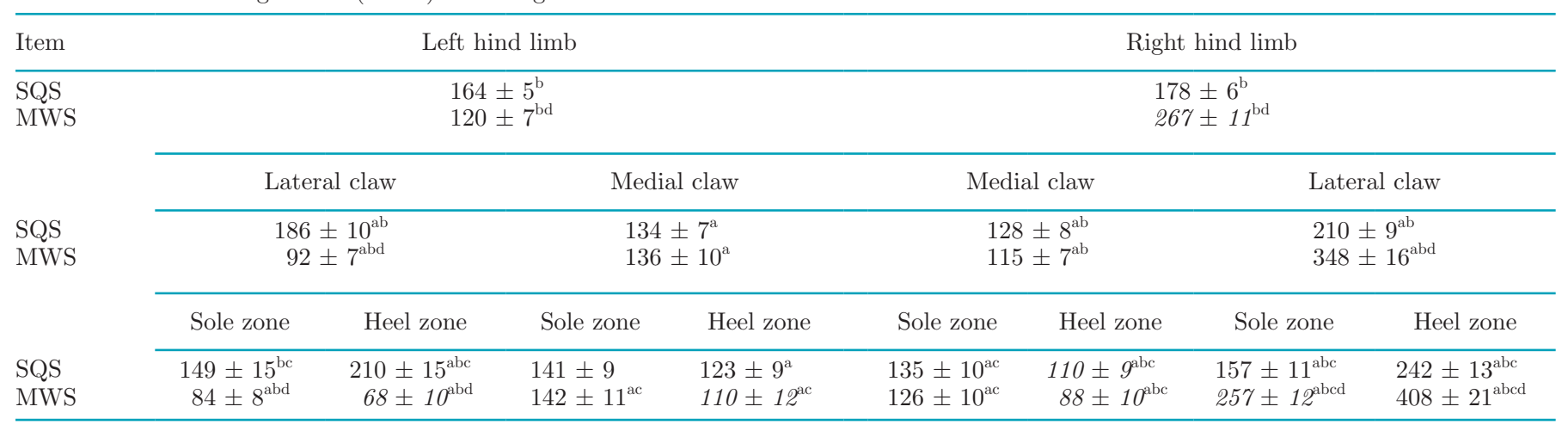

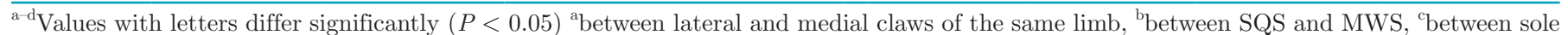
and heel zones, and ${ }^{\mathrm{d}}$ between the respective zones of the left and right hind limbs.

${ }^{1}$ Mean \pm SEM. Regular font for normally distributed data; italic font for non-normally distributed data.

A similar measuring system and experimental design have been successfully used in equine (van Heel et al., 2004) and bovine (van der Tol et al., 2002) studies, and the results of the latter were in agreement with our findings on load distribution at SQS. We preferred to examine standing cows because we assumed it is important in the pathogenesis of claw horn lesions. Dairy cows spend a considerable amount of their time standing, and deformation under static load continues for much longer time than during walking (Ouweltjes et al., 2016). Our measuring system, in contrast with those used in earlier studies (Toussaint Raven, 1971; van der Tol et al., 2002; Huth et al., 2005), was able to record load changes in both hind limbs simultaneously, which facilitated comparison of SQS and MWS.

The starting position with even loads in both hind limbs was achieved by gentle manipulation of the cows until SQS was achieved. The shift of weight to the right hind limb by manual pressure to the left hip was easily induced (Figure 3). However, the shift could not be standardized other than that measurements were not used when the cow lifted one limb off the ground or did not return toward SQS (no clear-cut MWS). We are aware that an induced shift of weight is different from naturally occurring weight shift. However, our cows were accustomed to being handled, and no excessive force was used. Weight shifting, such as that which occurs when yielding to other cows, is also part of the natural behavior of cows. We therefore assume that the sequence of events, once induced, was similar to that of a naturally occurring weight shift. Induced weight shifting was not accompanied by sliding or spreading of the claws in our experiment (Figure 3).

According to our measurements in SQS cows, only $33 \%$ of the entire hind limb vGRF was exerted on the medial claws together, and therefore one lateral claw carried the same weight as the 2 medial claws. We were surprised that the MWS position did not cause an in-

Table 4. Maximum pressures (in $\mathrm{kPa}$ ) of the hind limbs of 40 dairy cows with trimmed claws during square standing (SQS) and in the moment of maximum induced weight shift (MWS) to the right hind limb

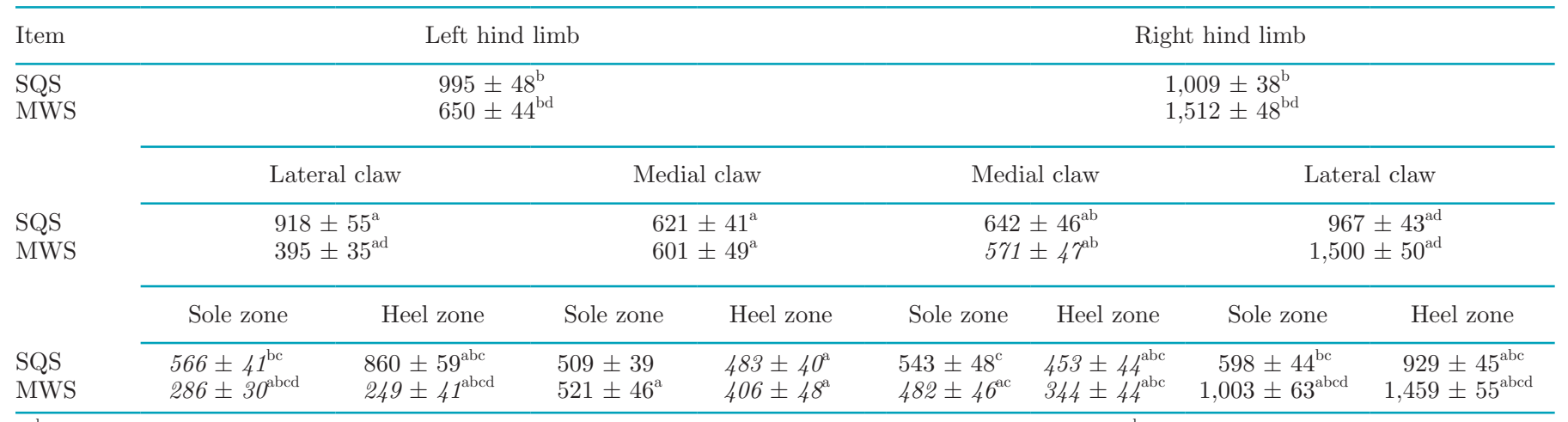

${ }^{\mathrm{a}-\mathrm{d}}$ Values with letters differ significantly $(P<0.05){ }^{\mathrm{a}}$ between lateral and medial claws of the same limb, ${ }^{\mathrm{b}}$ between SQS and MWS, ${ }^{\mathrm{c}}$ between sole and heel zones, and ${ }^{\mathrm{d}}$ between the respective zones of the left and right hind limbs.

${ }^{1}$ Mean \pm SEM. Regular font for normally distributed data; italic font for non-normally distributed data. 
crease in load in the medial claws. In fact, the loads in both medial claws were significantly smaller $(26 \%$ of the entire hind limb weight load) at MWS than at the SQS position. The principal change in claw load was therefore from the less-loaded lateral claw and its heel zone to the loaded contralateral lateral claw and its heel zone. This was in general agreement with the seminal assumptions of Toussaint Raven (1992), but the changes we were able to measure were much more pronounced. It can therefore be concluded that weight and weight shift in the hind limbs are largely at the cost of the lateral claws, and this may be a factor in the predisposition of these claws to claw horn lesions.

Our findings give rise to several questions about cause and effect of the load and pressure disparities between lateral and medial claws. Because these disparities were present at SQS and enhanced at MWS, an anatomical factor is likely the cause of the difference and has been discussed in the literature. One such anatomical feature might be the difference in length of the paired digits in cattle. Clinical and radiographic measurements have shown that the lateral digit is longer than the medial digit in the hind limbs of cattle and other even-toed ungulates (Keller et al., 2009; Muggli et al., 2016). A longer digit would predispose its claw to increased loading. Other anatomical features, such as the bony connection of the limb to the pelvis or an altered tendon insertion (Zantinga, 1973; Toussaint Raven, 1992; Manabe et al., 2002), may also play a role. Peripartum hormonal changes and change in digital cushion composition (Tarlton et al., 2002; Räber et al., 2006; Bicalho et al., 2009), although relevant in the pathogenesis of claw horn lesions, seem to be factors secondary to unequal loading because a negative effect on all claws equally and not primarily on the lateral hind claws would be expected. A larger amount of force and pressure applied to the longer lateral digits could initiate pathologic adaptation of the claw shape over time because of stimulation of horn growth (Hahn et al., 1984; Toussaint Raven, 1992). Consequently, the observed disparity in load could initiate pathologic changes that lead to claw horn lesions (Toussaint Raven, 1992; van der Tol et al., 2003).

Asymmetry in size and shape of paired hind claws was considerably less distinct in free-range cattle kept on large pasture fields throughout the year than in cows housed inside (Nuss et al., 2014). This finding indicates that the load is more evenly distributed to the claws on yielding natural ground. Unequal load distribution and pronounced asymmetry may be linked to housing cows indoors on hard surfaces. Claw horn is able to adapt to different weather conditions by water uptake and drying (Borderas et al., 2004). A harmful consequence of these claw characteristics is that in freestall housing, the claw horn is softened by moisture and weakened by chemical and bacterial activity and at the same time is in contact with hard and abrasive flooring. This inevitable maladaptation is likely to contribute to the high prevalence of claw horn lesions under current husbandry conditions. Because a higher load is acting on the longer digit, softening of the horn will have more effect on the lateral hind claws. In addition, the resistance to deformation of the claw horn is probably higher than that of natural ground. However, it is about 150 times lower than that of concrete (Franck et al., 2006).

Under experimental conditions, the yield stress of wall horn samples tested in bending was $10.8 \pm 5 \mathrm{MPa}$; for bulb horn samples, the yield stress was 56.0 MPa in compression (Franck et al., 2006). These pressures were considerably higher than the $1.5-\mathrm{MPa}$ maximum pressures we measured (Table 4). This indicates that the claw horn should be able to withstand the load pressures in standing cows without breaking, even during walking, when the vGRF on the limbs are about twice as high compared with the ones at SQS (van der Tol et al., 2003; Walker et al., 2010; Nuss et al., 2015). Thus, by simply assessing material properties and maximum pressures, there is no indication of an overload of claw horn. However, most claw horn lesions are believed to result from damage to the soft tissues of the claw (e.g., to the suspensory apparatus of the pedal bone and the digital cushion below the flexor tubercle; Hinterhofer et al., 2007). The yield point of these structures is likely to be lower than that of the claw horn, and their material properties are likely to be different. In another experiment, disruptions of the suspensory apparatus at the axial wall segment of the claws occurred at $2.27-\mathrm{MPa}$ tensile stress at $30 \mathrm{~mm} / \mathrm{min}$ (Maierl et al., 2002). This indicates that damage to the suspensory structures of the pedal bone may occur at lower stresses, especially when they are highly repetitive.

Findings of recent studies on the functional anatomy and biomechanics of the bovine hind claw (Maierl et al., 2002; Ouweltjes et al., 2016; Bach et al., 2017), combined with the results of our measurements, suggest that a pronounced distal displacement of the flexor tubercle of the pedal bone of the loaded lateral claw occurred at MWS. The imprint of the loaded lateral claw increased only a little $(9 \%)$, whereas the forces and pressures increased 3-fold at MWS (Tables 1-4). It is conceivable that the small increase in the size of the claw sole area cannot compensate for the huge increase in vGRF. Consequently, high mean and maximum pressures were acting on the claw sole at MWS. The imprints of the claws measured in our study were somewhat smaller than those obtained from direct measurements (Feszl, 1968; Nuss and Paulus, 2006) of sole surface areas, most likely because of limited spatial 
resolution of the pressure plate or irregularities in the stimulation of the sensors by the claw sole. For this reason, the sole was not divided into 4 to 6 zones (Mair et al., 1988; van der Tol et al., 2002; Carvalho et al., 2005), but instead was divided into 2 zones that could be reliably differentiated with our system.

In contrast to the loaded lateral claw, only $7.5 \%$ of the entire hind limb vGRF was exerted on the less-loaded lateral claw at MWS. Therefore, weight shifting in lame cows relieves weight bearing and pressure in a painful foot (Chapinal and Tucker, 2012). Unfortunately, this relief strategy, which is commonly seen in cows with sole ulcers, is inextricably linked to comparably high loading of the contralateral lateral claw, which may explain why sole ulcers are often bilateral.

Our measurements were made after foot trimming, but in agreement with other studies (Kehler and Gerwing, 2004; van der Tol et al., 2004), this did not eliminate the load disparity between the lateral and medial claws at SQS. Kehler and Gerwing (2004) showed that claw trimming had no long-term effect on the load patterns of the claws; the lateral claw always grows larger regardless of the increased load on the medial claws. This again points to an anatomical factor such as a length difference between the hind digits. It is also possible that our foot trimming procedure was inadequate, although our goal of aligning the level of the lateral sole with that of the medial sole was achieved. We made no further attempts to relieve the strain on the lateral claw. Therefore, it can be hypothesized that routine claw trimming of sound claws cannot prevent increased loading of a lateral claw at SQS and MWS. Our observations do not minimize the importance of claw trimming. Levelling, the creation of a correctly placed axial groove in the vicinity of the sole ulcer predilection site, and the relocation of the load from the heel zone to the apical sole zone are crucial for the prevention of sole ulcer.

An induced weight shift from one hind limb to the other accentuated the disparity of load distribution between paired hind limb claws in dairy cows. The total load on the loaded lateral claw and its heel zone was substantial at MWS. We believe that this observed disparity has the potential to damage the soft tissue structures of the lateral hind claw over time because of its repetitive nature resulting from the constant interaction of the weakened claw horn with hard flooring in most dairy operations.

\section{ACKNOWLEDGMENTS}

The authors thank Eva Weidmann and Luciano Schmid (Vetsuisse Faculty, University of Zurich, Switzerland) for their help with the planning and construc- tion of the measuring platform, Andres Cardona Gavaldon (Swiss Tropical and Public Health Institute, Basel, Switzerland) for his help with acquisition and collection of the data, and Carola Sauter-Louis (FriedrichLöffler-Institut, Greifswald, Germany) and Michael Hässig (Farm Animal Department, Vetsuisse Faculty, University of Zurich, Switzerland) for their statistical advice. The Cantonal University of Zurich is thanked for financing the study.

\section{REFERENCES}

Andersson, L., and K. Lundström. 1981. The influence of breed, age, body weight and season on digital diseases and hoof size in dairy cows. Zentralbl. Veterinarmed. A 28:141-151.

Bach, K., S. Nielsen, and N. Capion. 2017. Is the bovine pedal bone sinking around calving? Pages 175-176 in Proc. 19th International Symposium on Diseases of the Bovine Digit and 11th Conference on Lameness in Ruminants, Munich, Germany.

Bicalho, R. C., V. S. Machado, and L. S. Caixeta. 2009. Lameness in dairy cattle: A debilitating disease or a disease of debilitated cattle? A cross-sectional study of lameness prevalence and thickness of the digital cushion. J. Dairy Sci. 92:3175-3184.

Borderas, T. F., B. Pawluczuk, A. M. de Passille, and J. Rushen. 2004. Claw hardness of dairy cows: Relationship to water content and claw lesions. J. Dairy Sci. 87:2085-2093.

Cardoso, C. S., M. J. Hotzel, D. M. Weary, J. A. Robbins, and M. A. G. von Keyserlingk. 2016. Imagining the ideal dairy farm. J. Dairy Sci. 99:1663-1671.

Carvalho, V., R. Bucklin, J. Shearer, and L. Shearer. 2005. Effects of trimming on dairy cattle hoof weight bearing and pressure distributions during the stance phase. Trans. ASAE 48:1653-1659.

Chapinal, N., A. M. de Passille, J. Rushen, and C. B. Tucker. 2011. Short communication: Measures of weight distribution and frequency of steps as indicators of restless behavior. J. Dairy Sci 94:800-803.

Chapinal, N., and C. B. Tucker. 2012. Validation of an automated method to count steps while cows stand on a weighing platform and its application as a measure to detect lameness. J. Dairy Sci. 95:6523-6528.

Cramer, G., K. D. Lissemore, C. L. Guard, K. E. Leslie, and D. F. Kelton. 2009. The association between foot lesions and culling risk in Ontario Holstein cows. J. Dairy Sci. 92:2572-2579.

Feszl, L. 1968. Biometric studies on the ground surface of bovine claws and the distribution of weight on the extremities [in German]. Zentralbl. Veterinarmed. A 15:844-860.

Franck, A., G. Cocquyt, P. Simoens, and N. De Belie. 2006. Biomechanical properties of bovine claw horn. Biosyst. Eng. 93:459-467.

Griffiths, B. E., D. Grove White, and G. Oikonomou. 2018. A crosssectional study into the prevalence of dairy cattle lameness and associated herd-level risk factors in England and Wales. Front. Vet. Sci. 5:65.

Hahn, M. V., B. T. McDaniel, and J. C. Wilk. 1984. Genetic and environmental variation of hoof characteristics of Holstein cattle. J. Dairy Sci. 67:2986-2998.

Hinterhofer, C., V. Apprich, J. C. Ferguson, and C. Stanek. 2007. Modulus of elasticity and dry-matter content of bovine claw horn affected by the changes of chronic laminitis. Vet. J. 174:605-609.

Huth, C., A. Russke, B. Alsleben, H. Hamann, and O. Distl. 2005. Body and claw measurements as well as pressure distribution under the claws in heifers of different cattle breeds [in German]. Berl. Munch. Tierarztl. Wochenschr. 118:150-159.

Huxley, J., and M. Green. 2010. More for less: Dairy production in the 21st century. Vet. Rec. 167:712-713.

Kehler, W., and T. Gerwing. 2004. Effects of functional claw trimming on pressure distribution under hind claws of German Holstein cows. Pages 103-104 in Proc. 13th International Symposium and 5th Conference on Lameness in Ruminants, Maribor, Slovenia. 
Keller, A., M. Clauss, E. Muggli, and K. Nuss. 2009. Even-toed but uneven in length: The digits of artiodactyls. Zoology (Jena) 112:270-278

Maierl, J., R. Bohmisch, and M. Metzner. 2002. Biomechanical testing of the suspensory apparatus of the phalanx distalis in the claw of beef bulls. Wien. Tieraerztl. Monatsschr. 89:203-210.

Mair, A., W. Diebschlag, O. Distl, and H. Kräusslich. 1988. Measuring device for the analysis of pressure distribution on the foot soles of cattle. Zentralbl. Veterinarmed. A 35:696-704.

Manabe, H., K. Yoshitani, and R. Ishii. 2002. Consider function of deep digital flexor tendon in cattle claw trimming. Pages 422-424 in Proc. 12th International Symposium on Lameness in Ruminants, Orlando, FL.

Muggli, E., E. Weidmann, P. Kircher, and K. Nuss. 2016. Radiographic measurement of hindlimb digit length in standing heifers. Anat. Histol. Embryol. 45:463-468.

Nuss, K., E. Kolp, U. Braun, E. Weidmann, and M. Hassig. 2014. Claw size of Scottish Highland cows after pasture and housing periods [in German]. Schweiz. Arch. Tierheilkd. 156:433-440.

Nuss, K., and N. Paulus. 2006. Measurements of claw dimensions in cows before and after functional trimming: A post-mortem study. Vet. J. 172:284-292.

Nuss, K., N. M. Waldern, M. A. Weishaupt, and T. Wiestner. 2015. Kinetics of heifers and cows walking on an instrumented treadmill [in German]. Tieraerztl. Prax. Ausg. G Grosstiere Nutztiere 43:73-80.

Ossent, P., D. J. Peterse, and H. C. Schamhardt. 1987. Distribution of load between the lateral and medial hoof of the bovine hind limb. Zentralbl. Veterinarmed. A 34:296-300.

Ouweltjes, W., S. W. S. Gussekloo, C. W. Spoor, and J. L. van Leeuwen. 2016. A new technique using roentgen stereophotogrammetry to measure changes in the spatial conformation of bovine hind claws in response to external loads. Vet. J. 208:81-86.

Räber, M., M. R. Scheeder, P. Ossent, C. J. Lischer, and H. Geyer. 2006. The content and composition of lipids in the digital cushion of the bovine claw with respect to age and location-A preliminary report. Vet. J. 172:173-177.

Shearer, J. K., and S. R. van Amstel. 2017. Pathogenesis and treatment of sole ulcers and white line disease. Vet. Clin. North Am. Food Anim. Pract. 33:283-300.

Tarlton, J. F., D. E. Holah, K. M. Evans, S. Jones, G. R. Pearson, and A. J. Webster. 2002. Biomechanical and histopathological changes in the support structures of bovine hooves around the time of first calving. Vet. J. 163:196-204.

Toussaint Raven, E. 1971. Belastingsmeting aan de ondervoet van het rund. Tijdschr. Diergeneeskd. 96:1237-1243.

Toussaint Raven, E. 1992. Cattle Footcare and Claw Trimming. 3rd ed. Farming Press, Ipswich, UK.

van der Tol, P. P., J. H. Metz, E. N. Noordhuizen-Stassen, W. Back, C. R. Braam, and W. A. Weijs. 2002. The pressure distribution under the bovine claw during square standing on a flat substrate. J. Dairy Sci. 85:1476-1481.

van der Tol, P. P., J. H. Metz, E. N. Noordhuizen-Stassen, W. Back, C. R. Braam, and W. A. Weijs. 2003. The vertical ground reaction force and the pressure distribution on the claws of dairy cows while walking on a flat substrate. J. Dairy Sci. 86:2875-2883.

van der Tol, P. P., S. S. van der Beek, J. H. Metz, E. N. NoordhuizenStassen, W. Back, C. R. Braam, and W. A. Weijs. 2004. The effect of preventive trimming on weight bearing and force balance on the claws of dairy cattle. J. Dairy Sci. 87:1732-1738.

van Heel, M. C., A. Barneveld, P. R. van Weeren, and W. Back. 2004 Dynamic pressure measurements for the detailed study of hoof balance: The effect of trimming. Equine Vet. J. 36:778-782.

Walker, A. M., T. Pfau, A. Channon, and A. Wilson. 2010. Assessment of dairy cow locomotion in a commercial farm setting: The effects of walking speed on ground reaction forces and temporal and linear stride characteristics. Res. Vet. Sci. 88:179-187.

Zantinga, J. 1973. A comparative radiological and clinical study of the typical lesion of the sol (ulceration of the sole) in cattle. Neth. J. Vet. Sci. 5:88-97. 